\title{
Time critical? Does exposure time and brand information change users' evaluations of website appeal?
}

\author{
Daniel Bradley \\ Bournemouth University \\ Fern Barrow, Poole, BH12 5BB UK. \\ dbradley@bournemouth.ac.uk
}

\author{
Professor Siné McDougall \\ Bournemouth University \\ Fern Barrow, Poole, BH12 5BB UK. \\ smcdougall@bournemouth.ac.uk
}

\begin{abstract}
First impressions have been deemed important when making evaluations of website appeal. However, little is known about the long term nature of decision-making with respect to judgements of website appeal and how these may be shaped by other information available to us. This research aims to examine (a) how users' evaluations of website may change over time, (b) how brand information may change appeal evaluations (as opposed to judgements of products shown on a website) and (c) whether combining eye tracking with traditional subjective measures of appeal can inform us about the information used in making decisions about website appeal. Research outcomes will help to shape the formation of guidelines for future website development.
\end{abstract}

Website appeal. Visual aesthetics. Decision-making. Information framing. Eye movements.

\section{INTRODUCTION}

Despite the importance of the internet in modern life, the way in which evaluations of website appeal are made from the moment of initial perception through to later habitual experience with websites has received relatively little attention. Research has been fragmented examining either initial rapid often unconscious - website judgements (e.g. Lindgaard et al., 2006; 2011) or slower conscious decision-making (e.g. Hartmann, Sutcliffe \& de Angeli, 2008; Leder, Belke, Oeberst \& Augustin, 2004). Very little attention has been given to the processes which take place across time, encapsulating initial and later processing and the dynamic changes between unconscious and conscious processing.

\subsection{Rapid initial evaluations}

At the beginning of the decision 'timeline', research has clearly demonstrated that users' can make rapid reliable judgements of website appeal in 50200 milliseconds (Handy, Smilek, Geiger, Liu \& Schooler, 2008; Lindgaard et al., 2006; 2011; Tractinsky, Cokhavi, Kirschenbaum \& Sharfi., 2006). According to Norman (2004) these initial responses, known as 'visceral beauty responses', are immediate, holistic and physiologically based, and may influence an individual's later judgements. Norman argued that these initial responses create a 'halo effect' based on initial impressions which may affect later longer-term decision-making. It is clear that these rapid evaluations play an important role in the initial judgements we make when viewing a website, but what is yet to be explored is how these judgements influence our evaluations in the longer term.

\subsection{Later judgements of appeal}

Within consumer behaviour, theories proposing the presence of both conscious and unconscious processing within decision-making are not uncommon. One well known example is the elaboration likelihood model proposed by Petty \& Cacioppo, 1986 (see also Wegener, Petty, Blankenship \& Detweiler-Bedell, 2010). This model distinguishes between two forms of processing; unconscious automatic processing and more effortful conscious processing. This model predicts how decision-making which takes place through the use of more effortful, conscious processing will result in attitude changes which are more likely to be enduring and predictive of an individual's behaviour. However, the extent to which these later conscious decisions are influenced by our initial, often unconscious, evaluations is still unclear.

\section{Question 1: Do decisions about website appeal} change over time?

One possibility is that, as Norman argued, the halo effect based on initial impressions carries over, forming lasting opinions that are not changed by 
more effortful, conscious thinking. Alternatively, it may be that these initial impressions are only valid until more effortful conscious processing begins, altering our judgements of appeal. In order to examine this timeline - where different processes and strategies may be used to make decisions about websites - users' viewed websites for either a very short $(500 \mathrm{~ms})$, moderate $(6 \mathrm{~s})$ or unlimited presentation time, something which has yet to be considered in this way (see Tuch et al., 2012 for a review of website evaluation studies with different exposure times). This manipulation made it possible to investigate how judgements of appeal may change over time.

\subsection{Brand information and appeal judgements}

Recent research has shown that a single user review of website material can influence attitudes to a website over a five month period (Muchnik, Aral \& Taylor, 2013). We also know that information available prior to viewing a website such as our perceptions of a brand (e.g. Cho \& Oh, 2012; Park \& Lennon, 2009; de Angeli, Hartmann \& Sutcliffe, 2009) and whether or not that information is positive or negative (Hartmann, Sutcliffe \& de Angeli, 2008) can have an impact on decision making. However, the extent to which prior product knowledge affects judgements of website appeal as opposed to judgements about the products on the website - is not yet known.

\section{Question 2: Does brand information change perceptions of website appeal?}

Given that a single review can have a lasting influence on users' attitudes to a website, the role of one piece of brand information in determining users' evaluations of website appeal was examined in the present study. Participants were presented with positive or negative statements, or no information, about the brands presented in the websites they were about to view. If brand information influences judgements of appeal, then ratings of website appeal obtained when participants were given prior information should differ from those where no prior information was provided.

\subsection{Eye tracking and website appeal}

Recent work has suggested that eye tracking techniques can be combined with more traditional subjective measures making it possible to study website appeal at a more detailed level. Nainwal (2013) recently argued eye tracking during initial website experiences can be used to inform website design to enhance visceral appeal.

Question 3: Do eye movements systematically relate to judgements of website appeal and inform design?
However, Nainwal's assertion begs the question of how eye movements inform design if initial 'visceral' judgements can be made within $500 \mathrm{~ms}$ where only 1-2 saccades, at most, can be made (Greene \& Oliva, 2009; Lindgaard et al., 2006; 2011). Participants' eye movements were therefore examined in this study when they were able to view websites for either $500 \mathrm{~ms}$, $6 \mathrm{~s}$ or longer. This made it possible to determine whether or not there were systematic relationships between eye movements across the website and participants' evaluations of appeal.

\section{METHOD}

\subsection{Design}

A $3 \times 3$ mixed design was employed examining the effects of the time participants had to view a website (between subjects; $500 \mathrm{~ms}$ vs. $6 \mathrm{~s}$ vs. unlimited evaluation time) and brand information (within-subjects; positive vs. negative vs. no information) on participants' evaluations of website appeal.

\subsection{Materials and Procedure}

Each participant was shown 39 websites; for 13 of the websites positive brand information was presented prior to viewing the website, for 13 others negative information was presented, and for the remaining 13 no prior information was given. All 3 sets of 13 websites were matched on the basis of 5 key website appeal characteristics (i.e. creativity, diversity, simplicity, colourfulness and familiarity; see Moshagen \& Thielsch, 2010). Participants viewed websites via the Eyelink 1000 eye tracker. The procedure for each experimental trial was:

(i) Where applicable, participants were presented with a single piece of brand information to read.

(ii) The associated website was then presented for either $500 \mathrm{~ms}$, $6 \mathrm{~s}$ or unlimited time.

(iii) Participants were then asked to rate the website according to how appealing they found it on a scale of 1 (not appealing at all) to 7 (very appealing).

\section{POSSIBLE ANSWERS TO RESEARCH QUESTIONS}

Question 1: Do decisions about website appeal change over time? If Norman (2004) is correct, a halo effect resulting from initial user impressions may persist and decisions made when participants have $500 \mathrm{~ms}, 6 \mathrm{~s}$ or unlimited viewing times may be the same.

Question 2: Does brand information change perceptions of website appeal? This has yet to 
be examined within the literature. It is certainly likely to change views about the products related to a brand but we do not know how this may influence evaluations of website appeal.

Question 3: Do eye movements systematically relate to judgements of website appeal and inform design? For initial rapid decisions this seems unlikely since few saccades are made in $500 \mathrm{~ms}$, although systematic relationships between eye movements and decisions may emerge when users can view websites for longer.

\section{REFERENCES}

Cho, N., \& Oh, S. (2012). The Influence of Productbrand Web Sites on Attitudes toward Brand Image. Journal of Information Technology Applications \& Management, 19(3), 69-84.

De Angeli, A., Hartmann, J. \& Sutcliffe, A., (2009). The Effect of Brand on the Evaluation of Websites. In: Human-Computer Interaction INTERACT 2009: 12th IFIP TC 13 International Conference. Proceedings, Part II. Uppsala, Sweden, 24-28 August 2009. Berlin, Heidelberg: Springer Berlin Heidelberg, 638-651.

Greene, M. R., \& Oliva, A. (2009). The Briefest of Glances: The Time Course of Natural Scene Understanding. Psychological Science, 20(4), 464-472.

Handy, T.C., Smilek, D., Geiger, L., Liu, C. \& Schooler, J.W. (2008). ERP evidence for rapid hedonic evaluation of logos. Journal of Cognitive Neuroscience, 22, 124-138.

Hartmann, J., Sutcliffe, A., \& De Angeli, A. (2008). Towards a theory of user judgment of aesthetics and user interface quality. ACM Transactions On Computer-Human Interaction, 15(4).

Leder, H., Belke, B., Oeberst, A., and Augustin, D., (2004). A model of aesthetic appreciation and aesthetic judgements. British Journal of Psychology, 95(4), 489-508.

Lindgaard, G., Fernandes, G., Dudek, C., \& Brown, J. (2006). Attention web designers: You have 50 milliseconds to make a good first impression! Behaviour \& Information Technology, 25(2), 115-126.
Lindgaard, G., Dudek, C., Sen, D., Sumegi, L., \& Noonan, P. (2011). An exploration of relations between visual appeal, trustworthiness and perceived usability of homepages. ACM Transactions on Computer-Human Interaction (TOCHI), 18(1), 1.

Moshagen, M., \& Thielsch, M. T. (2010). Facets of visual aesthetics. International Journal of Human-Computer Studies, 68(10), 689-709.

Muchnik, L., Aral, S. and Taylor, S.J., (2013). Social influence bias: A randomized experiment. Science, 341(6146), 647-651.

Nainwal, S. (2013). Love at first sight: Using eyetracking to design for visceral appeal. In: Conference on Human Factors in Computing Systems (CHI), France, Paris, 27 April $-2^{\text {nd }}$ May 2003. ACM, New York, NY, USA.

Norman, D. A. (2004). Introduction to this special section on beauty, goodness, and usability. Human-Computer Interaction, 19(4), 311-318.

Park, M., \& Lennon, S. J. (2009). Brand name and promotion in online shopping contexts. Journal of Fashion Marketing and Management: An International Journal, 13(2), 149-160.

Petty, R. E., \& Cacioppo, J. T. (1986). The elaboration likelihood model of persuasion (pp. 1-24). New York: Springer.

Tuch, A.N., Presslaber, E.E., StöCklin, M., Opwis, K. and Bargas-Avila, J.A. (2012). The role of visual complexity and prototypicality regarding first impression of websites: Working towards understanding aesthetic judgments. International Journal of Human-Computer Studies, 70(11), 794-811.

Tractinsky, N., Cokhavi, A., Kirschenbaum, M., \& Sharfi, T. (2006). Evaluating the consistency of immediate aesthetic perceptions of web pages. International journal of human-computer studies, 64(11), 1071-1083.

Wegener, D. T., Petty, R. E., Blankenship, K. L., \& Detweiler-Bedell, B. (2010). Elaboration and numerical anchoring: Breadth, depth, and the role of (non-)thoughtful processes in anchoring theories. Journal of Consumer Psychology, 20(1), 28-32. 